\title{
Study of the kinetics and equilibria of the oligomerization reactions of 2-methylglyceric acid
}

\author{
A. W. Birdsall, C. A. Zentner, and M. J. Elrod \\ Department of Chemistry and Biochemistry, Oberlin College, Oberlin, Ohio, USA \\ Correspondence to: M. J. Elrod (mjelrod@oberlin.edu) \\ Received: 30 October 2012 - Published in Atmos. Chem. Phys. Discuss.: 21 November 2012 \\ Revised: 22 February 2013 - Accepted: 27 February 2013 - Published: 15 March 2013
}

\begin{abstract}
The presence of a variety of chemical species related to the gaseous precursor isoprene in ambient secondary organic aerosol (SOA) has stimulated investigations of the nature of SOA-phase chemical processing. Recent work has demonstrated that 2-methylglyceric acid (2-MG) is an important isoprene-derived ambient SOA component and atmospheric chamber experiments have suggested that 2-MG may exist in oligomeric form (as oligoesters) under conditions of low SOA water content. In order to better understand the thermodynamic and kinetic parameters of such oligomerization reactions, nuclear magnetic resonance techniques were used to study the bulk phase acid-catalyzed aqueous reactions (Fischer esterification) of 2-MG. While the present results indicate that 2-MG oligoesters are formed in the bulk phase with similar water content equilibrium dependences as observed in atmospheric chamber SOA experiments, the acid-catalyzed rate of the Fischer esterification mechanism may be too slow to rationalize the 2-MG oligoester production timescales observed in the atmospheric chamber experiments. Furthermore, it appears that unrealistically high ambient SOA acidities would also be required for significant 2-MG oligoester content to arise via Fischer esterification. Therefore, the present results suggest that other, more kinetically facile, esterification mechanisms may be necessary to rationalize the existence of 2-MG oligomers in atmospheric chamber-generated and ambient SOA.
\end{abstract}

\section{Introduction}

Isoprene, a biogenic volatile organic compound (VOC) with global emissions estimated at $600 \mathrm{Tg} \mathrm{yr}^{-1}$ (Guenther et al., 2006), has been shown through field measurements, labora- tory experiments, and modeling to be a significant source of secondary organic aerosol (SOA) (Carlton et al., 2009; Hallquist et al., 2009). Methacrolein, an important high- $\mathrm{NO}_{x}$ primary oxidation product of isoprene, as well as its derivative, methacryloylperoxy nitrate (MPAN), have been shown in atmospheric chamber experiments to form SOA that contains 2-methylglyceric acid (2-MG), oligoesters containing 2-MG units, and nitrated forms of each (Chan et al., 2010a; Surratt et al., 2006, 2010), though the mechanism by which MPAN oxidation leads to these SOA constituents remains unclear. Further analysis with mass spectrometry (MS) has served to characterize the specific isomeric structure of SOA constituents containing 2-MG subunits (Szmigielski et al., 2007). Sulfate esters of 2-MG, oligoesters and nitrated oligoesters have also been observed in chamber and ambient aerosol, and characterized using MS (Hatch et al., 2011; Surratt et al., 2007a, b; Gómez-González et al., 2008). 2-MG has been observed in ambient aerosols in multiple field studies (Hallquist et al., 2009; Carlton et al., 2009; Chan et al., $2010 \mathrm{~b}$ ), and in one case the presence of the 2-MG diester in ambient aerosol has also been reported (Jaoui et al., 2008).

This previous work suggests the source of lower-volatility 2-MG oligoesters (diester, triester, etc.), nitrate ester, and sulfate ester species may be the result of the following reactions:

$$
\begin{aligned}
& \text { 2-MG }+ \text { 2-MG } \rightarrow \text { 2-MG-diester }+\mathrm{H}_{2} \mathrm{O} \\
& \text { 2-MG-diester }+ \text { 2-MG } \rightarrow \text { 2-MG-triester }+\mathrm{H}_{2} \mathrm{O} \\
& \text { 2-MG }+\mathrm{HNO}_{3} \rightarrow \text { 2-MG-nitrate ester }+\mathrm{H}_{2} \mathrm{O} \\
& \text { 2-MG }+\mathrm{H}_{2} \mathrm{SO}_{4} \rightarrow \text { 2-MG-sulfate ester }+\mathrm{H}_{2} \mathrm{O}
\end{aligned}
$$

The complexity and incomplete species identification and quantitation in atmospheric chamber experiments make it 
Table 1. Initial mole fraction composition for perchloric acid controlled composition experiments. Total solution mass ranged from 1.6-2.1 g. Sum of listed mole fractions not equal to unity due to presence of $\mathrm{NaClO}_{4}\left(X_{\mathrm{NaClO}_{4}}=0.004-0.02\right)$ and DSS $\left(X_{\mathrm{DSS}}=\right.$ 0.00006-0.0002), components of the dried 2-MG solution.

\begin{tabular}{lccc}
\hline Solution \# & $X_{2-\mathrm{MG}}$ & $X_{\mathrm{DClO}_{4}}$ & $X_{\mathrm{D}_{2} \mathrm{O}}$ \\
\hline 1 & 0.0746 & 0.151 & 0.762 \\
2 & 0.0736 & 0.106 & 0.803 \\
3 & 0.0180 & 0.151 & 0.827 \\
4 & 0.0398 & 0.152 & 0.799 \\
5 & 0.0748 & 0.204 & 0.703 \\
6 & 0.0752 & 0.105 & 0.801 \\
7 & 0.0757 & 0.268 & 0.638 \\
\hline
\end{tabular}

difficult to extract information about these individual reaction steps. Most notably, the kinetic and thermodynamic properties, under atmospheric conditions, of the oligomerization reaction postulated to form oligoesters of 2-MG are not well-constrained. The existing chemical literature (Loudon, 1984) indicates that a likely oligoester formation mechanism is Fischer esterification, an acid-catalyzed condensation reaction (Fig. 1).

While the Fischer esterification mechanism involves an acid catalyzed rate limiting step, the hydroxyacids themselves can be a source of the acid catalyst. Specifically, there are reports in the literature of oligoester formation occuring for solutions of lactic (Filachione and Fisher, 1944; Vu et al., 2005; Espartero et al., 1996) and glyceric acid (Weber, 1989). However, this literature indicates that hydroxyacids can form significant quantities of oligoesters only under low water content conditions, and that the kinetics of the reactions can be very slow without added mineral acid catalysts. For example, studies of oligoester formation from glyceric acid (Weber, 1989) and lactic acid (Vu et al., 2005) used continuous direct removal of water (by evaporation and refluxing, respectively) in order to favorably shift the equilibrium towards oligoesters. While formal kinetics studies of oligoester formation from hydroxyacids seem to be absent from the literature, a report of oligoester formation from lactic acid indicated that establishment of equilibrium required 100 days at room temperature (Filachione and Fisher, 1944). The previous study on glyceric acid oligoester formation reported that the use of $0.005 \mathrm{M}$ sulfuric acid catalyst led to an oligomerization rate that was 140 times faster than the uncatalyzed rate (Weber, 1989), another indication that the uncatalyzed kinetics are very slow for ester formation from hydroxy acids.

The results of recent atmospheric chamber experiments suggest the importance of water content (i.e., relative humidity $(\mathrm{RH})$ ) in determining the equilibrium extent of oligomerization of 2-MG. One study of isoprene-derived SOA found a $69 \%$ reduction in 2-MG oligomer formation under humid $(\mathrm{RH}=90 \%)$ compared to dry $(\mathrm{RH}<2 \%)$ conditions, with
Table 2. Initial mole fraction composition for sulfuric and nitric acid controlled composition experiments. Total solution mass ranged from 1.4-2.0 g. Sum of listed mole fractions not equal to unity due to presence of $\mathrm{NaClO}_{4}\left(X_{\mathrm{NaClO}_{4}}=0.001-0.02\right)$ and DSS $\left(X_{\mathrm{DSS}}=0.00002-0.0003\right)$, components of the dried 2-MG solution.

\begin{tabular}{llrrr}
\hline Sol'n \# & Acid & $X_{2-\mathrm{MG}}$ & $X_{\text {acid }}$ & $X_{\mathrm{D}_{2} \mathrm{O}}$ \\
\hline 8 & $\mathrm{D}_{2} \mathrm{SO}_{4}$ & 0.00527 & 0.373 & 0.621 \\
9 & $\mathrm{D}_{2} \mathrm{SO}_{4}$ & 0.0216 & 0.366 & 0.609 \\
10 & $\mathrm{D}_{2} \mathrm{SO}_{4}$ & 0.0165 & 0.0775 & 0.903 \\
11 & $\mathrm{D}_{2} \mathrm{SO}_{4}$ & 0.0760 & 0.107 & 0.799 \\
12 & $\mathrm{D}_{2} \mathrm{SO}_{4}$ & 0.0754 & 0.206 & 0.701 \\
13 & $\mathrm{DNO}_{3}$ & 0.0214 & 0.389 & 0.586 \\
14 & $\mathrm{DNO}_{3}$ & 0.0747 & 0.210 & 0.703 \\
\hline
\end{tabular}

oligoesters from 2-MG up to 8 units in length under the dry conditions (Nguyen et al., 2011). A second investigation of isoprene-derived SOA found that the oligomer/2-MG ratio decreased to 0.20 at $45-88 \% \mathrm{RH}$ from 0.77 at $13-38 \% \mathrm{RH}$ (Zhang et al., 2011). A study of methacrolein-derived SOA found up to 5 2-MG units in oligomers at $<10 \% \mathrm{RH}$ (Chan et al., 2010a).

In this paper, we report measurements of the kinetics and equilibrium of the solution-phase acid-catalyzed 2-MG oligomerization reaction, using nuclear magnetic resonance (NMR) as the analytic technique. The ability of 2-MG to form sulfate and nitrate esters under acid-catalyzed conditions was also studied.

\section{Experimental}

\subsection{Synthesis of 2-methylglyceric acid}

2-MG was prepared using the same synthetic strategy as previously reported for the preparation of dihydroxy epoxides (Cole-Filipiak et al., 2010). Figure 2 outlines the synthetic pathway used for this experiment. All reactants were obtained commercially from Sigma-Aldrich unless stated otherwise, and were used as obtained, with given purities. Methacrylic acid (MA) $(99 \%, 10 \mathrm{~mL})$ was reacted with an excess of meta-chloroperoxybenzoic acid ( $m$ CPBA) $(\leq 77 \%, 27 \mathrm{~g})$ in reagent-grade dichloromethane $(100 \mathrm{~mL})$ to form methacrylic acid epoxide (MAE). Conversion was complete after 7 days of mixing at room temperature $\left(22^{\circ} \mathrm{C}\right)$, or $24 \mathrm{~h}$ under reflux conditions $\left(40^{\circ} \mathrm{C}\right)$. After filtering off excess $m$ CPBA (and the oxidation product meta-chlorobenzoic acid), $\mathrm{HClO}_{4}(70 \%, 50 \mathrm{~mL}, 0.2 \mathrm{M})$ was added to the mixture. $\mathrm{HClO}_{4}$ was used as the acid catalyst for the hydrolysis in order to avoid nucleophilic addition of the conjugate base $\left(\mathrm{ClO}_{4}^{-}\right.$is a very weak nucleophile) to MAE during the course of the ring opening reaction. MAE partitioned into the aqueous phase and was hydrolyzed into the diol, 2-MG, over the course of 8 days. The aqueous phase containing 2-MG 


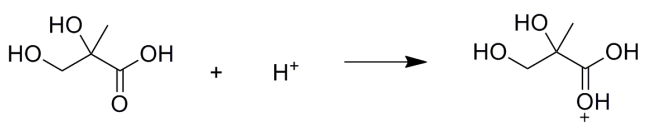

\section{2-MG}<smiles></smiles>

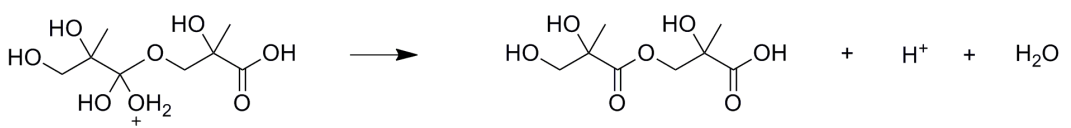

\section{2-MG-diester}

Fig. 1. Postulated Fischer esterification mechanism for 2-MG oligoester formation.

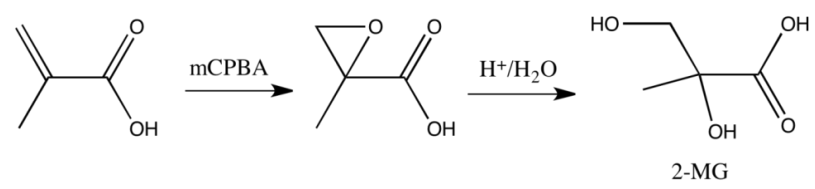

Fig. 2. Synthesis of 2-MG from methacrylic acid.

was separated and the strong acid component of the solution was neutralized with reagent-grade $\mathrm{NaOH}(97 \%)$ in deionized water solution $(10 \mathrm{~mL}, 1.0 \mathrm{M})$. No further purification of the dilute aqueous 2-MG solution was found to be necessary. The procedure for removing water from the dilute aqueous 2MG solution is described in Sect. 2.3. Using 4,4-dimethyl-4silapentane-1-sulfonic acid (DSS) (Cambridge Isotope Laboratories) as an internal standard, the NMR-determined yield of $2-\mathrm{MG}$ was found to be $104 \pm 10 \%$. ( ${ }^{1} \mathrm{H}$ NMR of pure $2-$ MG, Fig. S1).

\subsection{NMR technique}

2-MG diester formation was studied using an NMR-based technique developed previously to investigate the formation of isoprene-derived organosulfates and organonitrates (Darer et al., 2011). Spectra were collected with a Varian $400 \mathrm{MHz}$ NMR spectrometer. Default instrument parameters were used for all experiments except where specified below. Built-in auto-lock and gradient shim routines were performed before the first spectrum was collected in a session, but to help increase the temporal resolution of some kinetics experiments, re-locking and re-shimming were not performed if the sample was left in the spectrometer between the collection of spectra. Due to the relatively high concentration of $2-\mathrm{MG}$ in experimental solutions, a ${ }^{13} \mathrm{C}$ spectrum of 256 scans (collection time of $10 \mathrm{~min}$ ) resulted in a large enough signal-to-noise to allow for routine integration. Proton spectra used 8 scans $(30 \mathrm{~s})$. Chemical shifts were calibrated relative to the solvent $\mathrm{HDO}$ peak for all ${ }^{1} \mathrm{H}$ spectra, and relative to DSS for all ${ }^{13} \mathrm{C}$ spectra.

Due to overlap problems in the ${ }^{1} \mathrm{H}$ spectrum, quantitative integrations were found to be most reliable using ${ }^{13} \mathrm{C} N \mathrm{NR}$. To assess the reliability of using integrated peak areas from ${ }^{13} \mathrm{C}$ NMR spectra to determine relative concentrations in a spectrum, experiments were performed with extended relaxation times $(t 1=100 \mathrm{~s})$. It was found that the methyl and primary alcohol ${ }^{13} \mathrm{C}$ nuclei were fully spin relaxed and thus the integrated peak areas for those nuclei were directly proportional to relative concentration of the parent species, as is typically the case for ${ }^{1} \mathrm{H}$ spectra. Additionally, some peak overlap was observed in the methyl region of ${ }^{13} \mathrm{C}$ spectra. Consequently, the relative areas of the primary alcohol peaks from ${ }^{13} \mathrm{C}$ spectra with a $1.0 \mathrm{~s}$ relaxation time were most commonly used in the kinetics and equilibrium analysis procedures.

Two-dimensional ${ }^{1} \mathrm{H}^{-1} \mathrm{H} \quad$ Correlation Spectroscopy (COSY) and ${ }^{1} \mathrm{H}_{-}{ }^{13} \mathrm{C}$ Heteronuclear Multiple Bond Correlation (HMBC) experiments (Braun et al., 1998) were performed to confirm peak assignments and establish connectivity across the ester linkage in the diester species. The COSY experiment was performed on a sample from a dehydration experiment (Sect. 2.3) in sulfuric acid using default instrument settings. An HMBC experiment was performed using a sample from a controlled composition experiment in $\mathrm{DClO}_{4}$ (see Sect. 2.4) containing 2-MG and diester. This spectrum was collected using the built-in gHMBCAD pulse sequence, which is gradient enhanced and contains an adiabatic pulse. Non-default acquisition parameters were 1024 increments, 32 scans/increment, and a 2.0 s relaxation delay. 


\subsection{Dehydration experiments}

Preliminary studies of the esterification of 2-MG were made with "dehydration experiments", in which aliquots were collected from an aqueous solution of 2-MG and monitored with NMR over time as a vacuum system reduced the solution's water content. This process of decreasing water content over time is analogous to how water loss might occur in ambient aerosols as relative humidity decreases. These experiments were performed using both the "neutralized" dilute 2-MG solution (i.e., a solution whose strong acid content has been neutralized, even though the solution remains acidic due to the acidity of 2-MG) whose preparation was described in Sect. 2.1, as well as with solutions containing sulfuric or perchloric acid. The acidified solutions were prepared by removing some water from the dilute 2-MG solution by rotary evaporation, and then adding concentrated $\mathrm{H}_{2} \mathrm{SO}_{4}$ or $\mathrm{HClO}_{4}$ to obtain a solution whose concentration was $1 \mathrm{M}$ in added mineral acid. The initial concentration of 2-MG, near $1 \mathrm{M}$ in each solution, was quantified with use of a DSS internal standard. The initial solution volume in each experiment was approximately $20 \mathrm{~mL}$.

Each solution was transferred to a glass trap with a magnetic stir bar, and attached to a vacuum pump. Water was removed by exposing the solution to a vacuum with pressure gradually lowered to $<1$ torr, with vigorous stirring and immersion in a water bath with a temperature maintained at $295 \mathrm{~K}$. As the volume of the solution decreased, and acidity and 2-MG concentration increased, $1 \mathrm{~mL}$ aliquots were collected at different points as the dehydration progressed. Because the density of the solution could change with its composition, mass balance calculations were used to track the water content of the solution as water evaporated and samples were removed. Samples were collected at four different levels of dehydration: when no water had been removed, after approximately half the volume was lost, after approximately three-quarters of the volume was lost, and when the volume and vacuum pressure were observed to drop no further (observed at $2-3 \mathrm{~mL}$, and 500-600 millitorr, respectively). This endpoint was achieved approximately $2 \mathrm{~h}$ after first starting to remove water from the solution. For every dehydration experiment, the mass balance was found to be negative when the final, most concentrated sample was collected, i.e., more mass had been lost than the calculated initial water content of the solution. This implies that effectively no water was left in the most concentrated solutions, and that perhaps other, less volatile solution components also had evaporated.

\subsection{2-MG self-catalyzed esterification experiments}

To assess the ability of 2-MG to catalyze 2-MG Fischer esterification with no addition source of acidity, concentrated 2-MG was prepared as described in Sect. 2.3, using dilute 2-MG solutions whose strong acid content had been neutralized. (No samples were collected with intermediate amounts of water loss.) Based on mass loss of the solution after exposure to vacuum, the entirety of the water was removed, resulting in a clear, viscous solution consisting of 2-MG $(86 \%$ $w / w), \mathrm{NaClO}_{4}(14 \%)$ and DSS $(0.45 \%)$. Comparison of the ${ }^{1} \mathrm{H}$ NMR peak integration of 2-MG with involatile DSS confirmed that 2-MG had not evaporated. The composition of this concentrated 2-MG solution was monitored over time using ${ }^{1} \mathrm{H}$ NMR. Because the rate of esterification was found to be very slow (as discussed below), concentrated 2-MG prepared in this way was used for the controlled composition experiments (Sect. 2.5).

\subsection{Controlled composition experiments}

In order to investigate the kinetics and equilibrium of solution-phase 2-MG reactions in a more systematic and less time-consuming way than the dehydration experiments (Sect. 2.3), "controlled composition experiments" were performed. Because of the need for high concentrations of deuterated species for NMR locking purposes, the composition of the various solutions was limited to relatively high acid (for which deuterated species are available) to 2-MG (for which only the normal isotope was synthesized) ratios.

For each controlled composition experiment, 25-600 mg of concentrated 2-MG solution (Sect. 2.4) was measured with an analytical balance into a small beaker. A known volume of $\mathrm{D}_{2} \mathrm{O}$ (Cambridge Isotope Laboratories) was added to the beaker with a micropipettor (0-950 microliters). The mixture was stirred vigorously until the 2-MG was dissolved. The beaker was then immersed in a room temperature water bath while a known volume of concentrated $\mathrm{D}_{2} \mathrm{SO}_{4}(97 \%)$, $\mathrm{DClO}_{4}(68 \%)$ or $\mathrm{DNO}_{3}(68 \%)$ was added dropwise with a micropipettor (50-1000 microliters), making the total non-2MG volume of the solution $1.000 \mathrm{~mL}$. (All deuterated acid solutions were $99+$ atom $\% \mathrm{D} ; \mathrm{DNO}_{3}$ was obtained from Acros Organics.) After 2 min of vigorous stirring, the solution was transferred to a $5 \mathrm{~mm}$ NMR tube and both ${ }^{13} \mathrm{C}$ and ${ }^{1} \mathrm{H}$ spectra were collected at regular intervals as reaction(s) progressed.

\section{Results and discussion}

\subsection{NMR assignments}

\subsubsection{D ${ }^{1} \mathrm{H}$ and ${ }^{13} \mathrm{C}$ spectra of 2-MG, diester, and triester}

Due to the highly acidic nature of many of the solutions analyzed with NMR, the chemical shifts of organic components compared to the solvent HDO peak were highly variable in ${ }^{1} \mathrm{H}$ spectra (and to a smaller extent variable in ${ }^{13} \mathrm{C}$ spectra), but the relative position of peaks due to hydrogen or carbon atoms of 2-MG and its derivatives remained almost constant across experiments, allowing for peak assignments to remain obvious across experiments with different acid content. 
Table 3. ${ }^{13} \mathrm{C}$ NMR assignments for 2-MG and derivatives (in ppm, relative to DSS) for Solution 1. See Fig. 3 for key to labels of units. Tentative, partial triester assignments are given (the absence of the full complement of peaks is presumably due to overlap with 2-MG and 2-MG-diester species).

\begin{tabular}{lllllll}
\hline & $a$ & $b$ & $c$ & \multicolumn{3}{c}{ triester } \\
\hline $\mathrm{CH}_{3}$ & 23.7 & $24.0,24.1$ & 23.7 & - & - & - \\
$1^{\circ} \mathrm{COH}$ & 70.2 & $72.6,72.7$ & 70.2 & 67.8 & - & - \\
$3^{\circ} \mathrm{COH}$ & 78.7 & $77.1,77.1$ & $79.1,79.2$ & 77.5 & 77.0 & - \\
$\mathrm{COOH}$ & 180.0 & 178.9 & 177.4 & 178.8 & 177.3 & 176.4 \\
\hline
\end{tabular}

Peak assignment of the 2-MG diester in both ${ }^{1} \mathrm{H}$ and ${ }^{13} \mathrm{C}$ spectra was aided by a previous NMR-based study of the oligomerization of lactic acid, a hydroxyacid similar to 2MG (Espartero et al., 1996). The same naming convention for labeling the units of the 2-MG oligoester species was used as in the lactic acid study (Fig. 3). Additionally, since each oligoester unit contains similar groups of carbon and hydrogen atoms, ${ }^{1} \mathrm{H}$ and ${ }^{13} \mathrm{C}$ spectra could be divided into regions corresponding to each group: methylene $\left(\mathrm{CH}_{2}\right)$ and methyl $\left(\mathrm{CH}_{3}\right)$ regions in ${ }^{1} \mathrm{H}$ spectra; carboxyl $(\mathrm{COOH})$, tertiary alcohol $\left(3^{\circ} \mathrm{COH}\right)$, primary alcohol $\left(1^{\circ} \mathrm{COH}\right)$ and methyl $\left(\mathrm{CH}_{3}\right)$ regions in ${ }^{13} \mathrm{C}$ spectra. A sample ${ }^{13} \mathrm{C}$ spectrum is given in Fig. $4 ;{ }^{13} \mathrm{C}$ peak assignments for $2-\mathrm{MG}$, diester, and triester (partial assignment) are given in Table 3. Formation of oligoesters of three units (triester) was postulated to account for the appearance of smaller features in ${ }^{1} \mathrm{H}$ and ${ }^{13} \mathrm{C}$ spectra in solutions with extensive diester formation. Tentative, partial triester assignments were possible for peaks visible in ${ }^{13} \mathrm{C}$ spectra for solutions with considerable diester formation, with the clearest separation of peaks visible in the carboxyl region. An extended discussion of the rationale behind the ${ }^{13} \mathrm{C}$ assignments, as well as ${ }^{1} \mathrm{H}$ spectra and assignments, are available in the Supplement.

\subsubsection{2-D spectral analysis of 2-MG diester and sulfate ester}

Collection of 2-D COSY and HMBC spectra was necessary to confirm peak assignments made above. $\mathrm{H}-\mathrm{H}$ correlations from the COSY spectrum of a dehydration experiment containing sulfuric acid provided correlations between pairs of peaks in the methylene region corresponding to the two nonequivalent $\mathrm{CH}_{2}$ protons in 2-MG, the sulfate ester, and each unit of the diester. The 2- and 3-bond C-H correlations from the HMBC spectrum of a controlled composition experiment containing 2-MG diester were consistent with the formation of a single 2-MG diester isomer: that which formed by reaction of the carboxyl group of one 2-MG unit with the primary hydroxyl group of another 2-MG unit. Additional ${ }^{1} \mathrm{H}$ or ${ }^{13} \mathrm{C}$ peaks that would arise from the product of an esterification reaction at the tertiary hydroxyl group were not observed.

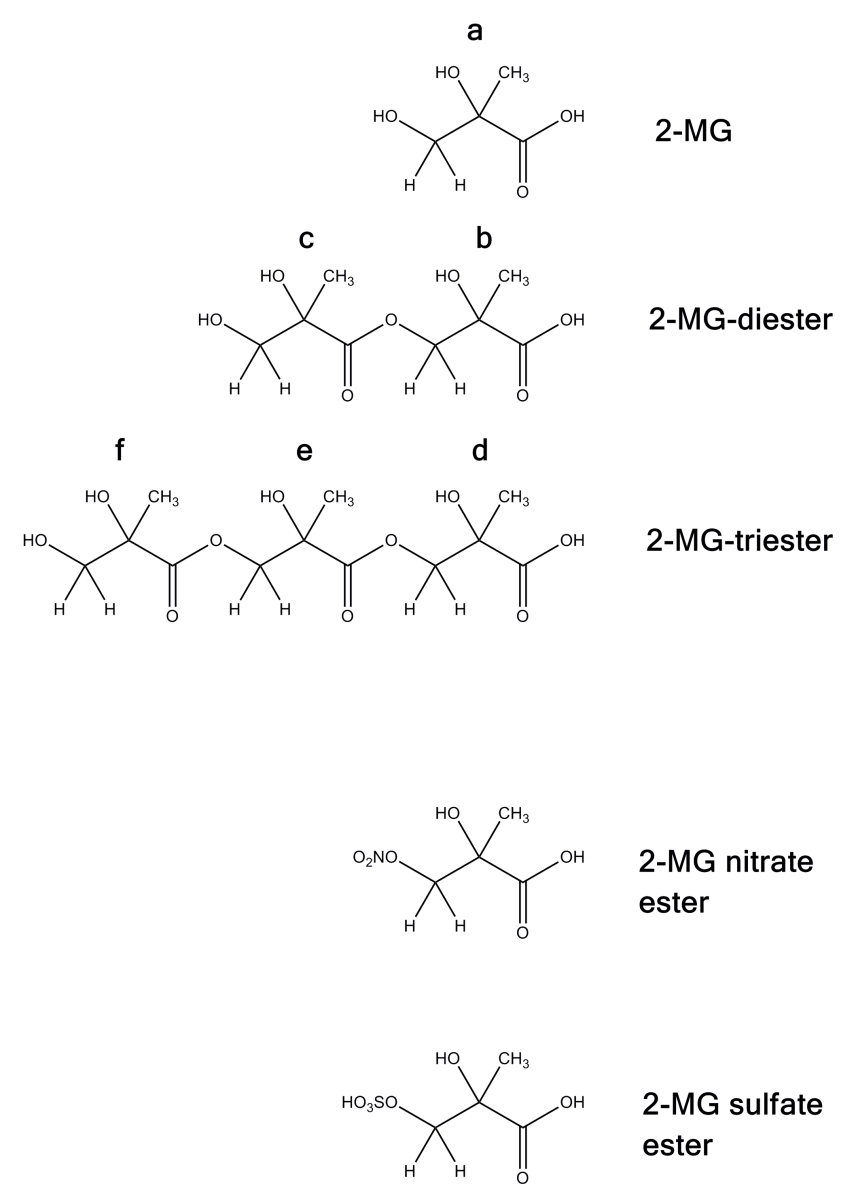

Fig. 3. Labels used for units of 2-MG (a) and associated species in NMR assignments.

Annotated COSY and HMBC spectra are available as figures in the Supplement.

\subsubsection{D ${ }^{1} \mathrm{H}$ and ${ }^{13} \mathrm{C}$ spectra of 2-MG diester, nitrate ester and sulfate ester}

In addition to analysis of the COSY spectrum (Sect. 3.1.2), ${ }^{13} \mathrm{C}$ and ${ }^{1} \mathrm{H}$ spectral assignments of the 2-MG nitrate and sulfate esters were made by comparing spectra of nitric and sulfuric acid experiments to perchloric acid experiments. Figure 5 presents a sample ${ }^{13} \mathrm{C}$ spectrum from a nitric acid controlled composition experiment. (Additional ${ }^{1} \mathrm{H}$ and ${ }^{13} \mathrm{C}$ spectra containing 2-MG nitrate and sulfate esters are available in the Supplement, Figs. S3-S5.) To determine which 2-MG hydroxyl group was being substituted with a nitrate or sulfate group, the ${ }^{13} \mathrm{C}$ chemical shifts of the nitrate and sulfate ester species were compared with the shifts of previous NMR studies of nitrate and sulfate ester formation of species that were structurally related to 1,2,3,4-butanetetrol (Minerath et al., 2009). That study found that the carbon atom at the site of sulfate ester or nitrate formation exhibited a large relative shift of downfield (7-11 ppm), and the adjacent 


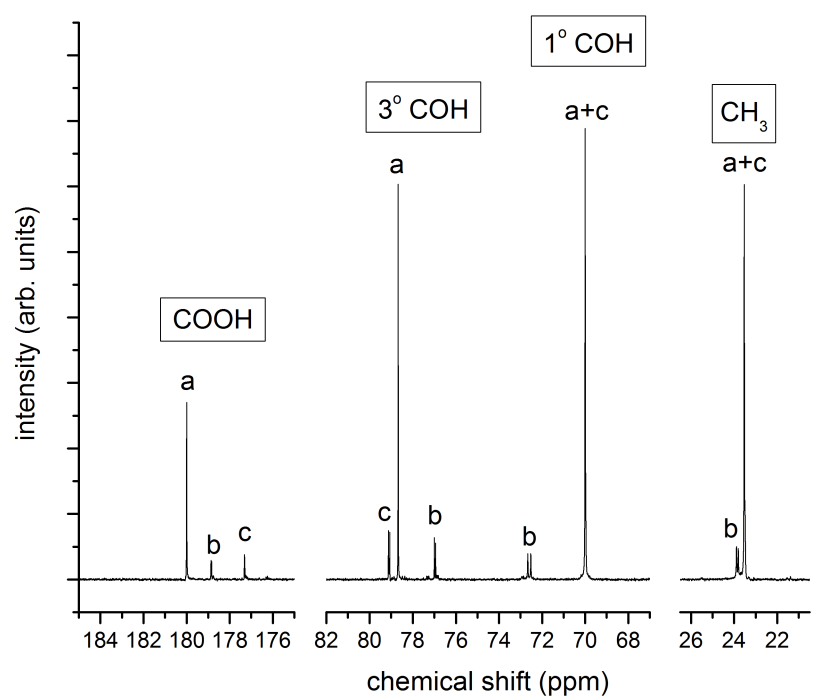

Fig. 4. ${ }^{13} \mathrm{C}$ spectrum of 2-MG and 2-MG diester (Solution 1). See Fig. 3 for key to labels.

carbon atom a smaller relative shift upfield (2-4 ppm) compared to the alcohol species. In this study, the 2-MG nitrate and sulfate ester both exhibited a relative shift of the primary carbon downfield (5-9 ppm) and the tertiary carbon upfield (2-3 ppm), consistent with the assignment of both reactions occurring at the primary hydroxyl group. No second group of peaks due to formation of the tertiary nitrate or sulfate ester was observed. Peak assignments are summarized in Tables 4 and $5\left({ }^{13} \mathrm{C}\right)$ and $\mathrm{S} 1\left({ }^{1} \mathrm{H}\right)$.

Though nitrated 2-MG oligoesters have been reported in atmospheric chamber experiments (Chan et al., 2010a), these species were not observed in the present experiments. However, our experimental conditions (relatively high water content) were not ideal for the observation or identification of those species, given the relatively small oligoester yields, the thermodynamic preference for oligoesters as compared to nitrate esters, and the problem of overlapping NMR peaks for the expected species.

\subsection{Aqueous solubility of organic species}

Because the reaction solutions consisted of large concentrations of organic components in relatively small amounts of water, it was important to assess the possibility that phase separation was occurring. As in ambient aerosols, the possibility of liquid-liquid phase separation is important to consider (Zuend and Seinfeld, 2012). However, based on the analysis described below, we do not believe that any of the species partitioned out of the aqueous phase to any measurable extent.

Two methods were used to check for the possibility of liquid-liquid phase separation of organic components out of the aqueous phase. First, for several experimental solutions,

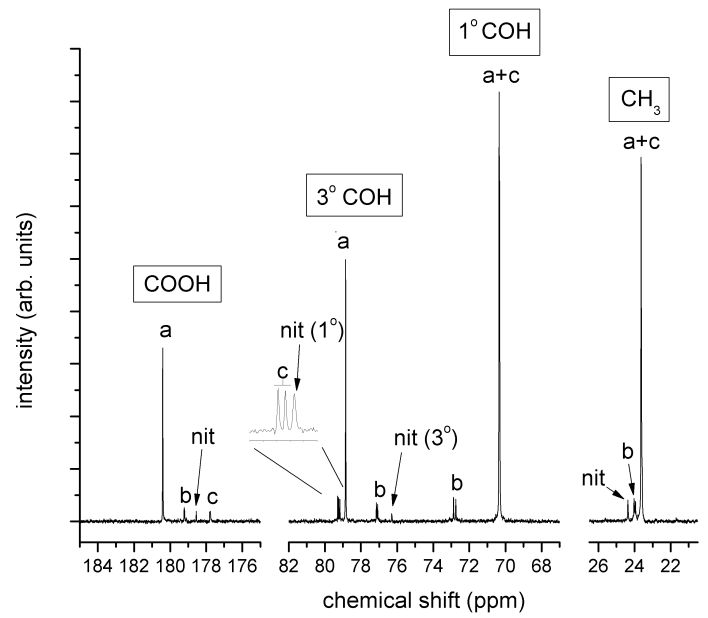

Fig. 5. ${ }^{13} \mathrm{C}$ spectrum of 2-MG, 2-MG diester and nitrate ester (Solution 14). See Fig. 3 for key to labels.

Table 4. ${ }^{13} \mathrm{C}$ NMR assignments for 2-MG and derivatives (in ppm, relative to DSS) for Solution 12. See Fig. 3 for key to labels of units.

\begin{tabular}{lllll}
\hline & $a$ & $b$ & $c$ & sulfate ester \\
\hline $\mathrm{CH}_{3}$ & 23.7 & $24.0,24.1$ & 23.7 & 23.9 \\
$1^{\circ} \mathrm{COH}$ & 70.0 & $72.6,72.7$ & 70.0 & 75.6 \\
$3^{\circ} \mathrm{COH}$ & 78.7 & $76.9,77.0$ & $79.1,79.1$ & 77.1 \\
$\mathrm{COOH}$ & 180.1 & 179.0 & 177.4 & 178.9 \\
\hline
\end{tabular}

the total integrated area of the methyl region was measured and compared to the DSS peak, used as an internal standard, in multiple ${ }^{1} \mathrm{H}$ NMR spectra over the course of the reaction. Because all observed reactions (self-esterification, sulfate esterification, nitrate formation) preserve the methyl peak at approximately the same location, the area of the methyl region relative to the DSS peak should correspond to the initial 2-MG concentration and stay constant over time, if all 2-MG derivatives remain in the aqueous phase. It was found that across all analyzed ${ }^{1} \mathrm{H}$ spectra, the methyl region integration corresponded to the presence of $85-124 \%$ of the initial 2MG concentration, with no clear trend of product loss for a particular experiment over time. Second, the AIOMFACmodeled molar activity coefficients for 2-MG and diester in equilibrium solutions were calculated to be less than unity (see Sect. 3.4 for detailed discussion of the use of AIOMFAC). As a first approximation, this implies both species are stable in aqueous solutions at the experimental observed equilibrium compositions.

\subsection{Dehydration experiment results}

2-MG diester and sulfate ester formation was observed with the dehydration experiments, but only in highly concentrated (in 2-MG and in both 2-MG and sulfuric acid, respectively) samples. Using sulfuric acid as the strong acid, with an 
Table 5. ${ }^{13} \mathrm{C}$ NMR assignments for $2-\mathrm{MG}$ and derivatives (in ppm, relative to DSS) for Solution 14. See Fig. 3 for key to labels of units.

\begin{tabular}{lllll}
\hline & $a$ & $b$ & $c$ & nitrate ester \\
\hline $\mathrm{CH}_{3}$ & 23.7 & $24.0,24.1$ & 23.7 & 24.4 \\
$1^{\circ} \mathrm{COH}$ & 70.4 & $72.8,72.9$ & 70.4 & 79.2 \\
$3^{\circ} \mathrm{COH}$ & 78.9 & $77.1,77.2$ & $79.3,79.3$ & 76.4 \\
$\mathrm{COOH}$ & 180.5 & 179.3 & 177.8 & 178.6 \\
\hline
\end{tabular}

estimated composition of $37 \% \mathrm{H}_{2} \mathrm{SO}_{4}, 8 \%$ 2-MG and $54 \%$ $\mathrm{H}_{2} \mathrm{O}$, the diester:2-MG mole fraction ratio was 0.14 at equilibrium, with an estimated formation lifetime of $11 \mathrm{~h}$. Under more extreme conditions of estimated $76 \% \mathrm{H}_{2} \mathrm{SO}_{4}, 17 \%$ 2-MG and $7 \%$ water, the diester:2-MG mole fraction ratio was 0.80 at equilibrium, again with an approximate formation lifetime of $\sim 11 \mathrm{~h}$. Sulfate ester formation was also observed in each case, which was competitive with the kinetics of diester formation.

Perchloric acid experiments were also performed, but the higher vapor pressure of perchloric acid led to increased mass loss upon exposure to a vacuum, making the solution composition even more uncertain. Starting with $20.33 \mathrm{~g}$ of solution of mass composition $10 \% \mathrm{HClO}_{4}, 19 \%$ 2-MG and $67.4 \%$ $\mathrm{H}_{2} \mathrm{O}$, mass was then reduced under vacuum to $2.79 \mathrm{~g}$. At equilibrium, the diester:2-MG mole fraction ratio was determined to be 1.32 .

\subsection{Self-catalyzed 2-MG esterification kinetics}

Two solutions containing concentrated 2-MG (according to mass balance calculations, these solutions contained very little water) and no added mineral acid were kept at room temperature and monitored over the course of months to assess the degree to which self-catalyzed oligomerization occurred. Both solutions were found to be composed of about $2 \%$ diester initially and about $7 \%$ diester after 6 months time. The initial diester formation probably occured during the very high acidity conditions that were present during the hydrolysis of the epoxide precusor. Using the observed net 2-MG loss of $5 \%$ over the 6 month period, a first order lifetime of about 3600 days is obtained for the self-catalyzed formation of the diester.

\subsection{Modeling solution activities with AIOMFAC-web}

Because measurable 2-MG reactivity required solutions with very high concentrations of $2-\mathrm{MG}$ and strong acid, both the kinetics and equilibrium analyses required the determination of the activities of the components of these non-ideal solutions. Previous NMR-based kinetics studies using concentrated strong acid solutions found that the excess acidity model provided proton activity values that were consistent with the observed acid-dependent kinetics results for various types of reactions (Minerath et al., 2008; Casale et al., 2007; Cox and Yates, 1978). The present experiments, however, are complicated by the presence not just of considerable amounts of strong acid, but also of organic components, namely of 2-MG and derivatives. To account for the presence both of strong acid and organic components of the reaction mixtures, the web-accessible version of the Aerosol Inorganic-Organic Mixtures Functional groups Activity Coefficients model (AIOMFAC-web) was used (http://www.aiomfac.caltech.edu; Zuend and Seinfeld, 2012; Zuend et al., 2008, 2010, 2011). This model uses a group-contribution approach for organic components, in which organic molecules are considered in terms of their component functional groups. This approximation is expected to work well for compounds with isolated functional groups. AIOMFAC-web neglects intramolecular effects arising from interactions between nearby functional groups (Zuend et al., 2011), suggesting that the model might be somewhat less accurate for multifunctional compounds like 2-MG and its potential reaction products.

The proton activities for totally inorganic sulfuric acid solutions ranging from 10 to $70 \% \mathrm{w} / \mathrm{w}$ were calculated via AIOMFAC-web and compared to published excess acidities model data (Cox and Yates, 1978). A high degree of correlation was found to exist between the AIOMFAC-web proton activities and excess acidities for the inorganic solutions, thus suggesting that the AIOMFAC-web proton activites are as appropriate as the well-tested excess acidity model in the parameterization of acid-catalyzed kinetics data.

For AIOMFAC-web analysis of 2-MG aqueous solution data, the model included specific parameters for the presence of sulfuric and nitric acid. Since parameters for perchloric acid were not available in AIOMFAC-web, nitric acid was used as the proxy for perchloric acid solutions, since both acids are monoprotic oxy acids, and are likely to have similar solution properties. Additionally, because AIOMFACweb does not currently include fully defined interactions for ester groups, an ether group was used as the proxy for the ester groups present in the diester species, an approximation that has been previously successfully used (Zuend and Seinfeld, 2012). As expected, the calculated proton activities for concentrated 2-MG/acid solutions using AIOMFAC-web deviated from activities calculated by AIOMFAC-web for the acid solutions alone by a factor of 0.6 to 1.4 , thus indicating the non-ideal nature of the solutions (Table S2).

\subsection{Equilibrium formation of 2-MG diester, nitrate ester, and sulfate ester}

\subsubsection{Accounting for higher order oligoesters}

As discussed in Sect. 3.1.1, small concentrations of triester products were tentatively identified in some solutions. Even though the triester concentrations could be not reliably quantified, it is of interest to estimate those concentrations for the purposes of determining whether they need to be considered 
Table 6. Equilibrium mole fraction composition for perchloric acid controlled composition experiments. Sum of listed mole fractions not equal to unity due to presence of $\mathrm{NaClO}_{4}$ and trace DSS.

\begin{tabular}{lrrrrr}
\hline Solution \# & $X_{\text {2-MG diester }}$ & $X_{2-\mathrm{MG}}$ & $X_{\mathrm{DClO}_{4}}$ & $X_{\mathrm{D}_{2} \mathrm{O}}$ & $K_{\text {eq }}^{\prime}$ \\
\hline 1 & 0.0043 & 0.0659 & 0.151 & 0.767 & 0.76 \\
2 & 0.0089 & 0.0559 & 0.106 & 0.812 & 2.3 \\
3 & 0.0000555 & 0.0180 & 0.151 & 0.827 & 0.14 \\
4 & 0.00380 & 0.0322 & 0.152 & 0.803 & 3.0 \\
5 & 0.0187 & 0.0374 & 0.204 & 0.722 & 9.6 \\
6 & 0.0101 & 0.0549 & 0.105 & 0.812 & 2.7 \\
7 & 0.0241 & 0.0275 & 0.268 & 0.663 & 21 \\
\hline
\end{tabular}

in the modeling of the equilibrium and kinetics data for the diester forming reaction. In a previous study of lactic acid oligomer formation, it was found that equilibrium constant for the diester formation was approximately equal to the equilibrium constants for the higher order oligoester formation reactions (Vu et al., 2005). If it is assumed that 2-MG oligioester formation is also characterized by single equilibrium constant for each step, it is possible to estimate the triester formation based on the measurement of the diester formation. For example, in many of the experiments, the equilibrium diester concentration was on the order of 10-20\% of the equilibrium 2-MG concentration; therefore, assuming an identical equilibirum constant for the triester formation, only $1-2 \%$ of the equilibrium 2-MG concentration is expected to be found in the form of triesters. Because of the expected small extent of triester formation in these solutions, the presence of oligoesters larger than the diester were neglected in the equilibrium and kinetics analyses. In addition, no evidence was obtained for the production of sulfate and nitrate esters derivatives of the 2-MG diesters.

\subsubsection{Equilibrium constant determination approach}

For the controlled composition experiments, spectra were collected until no change in the relative integration of different species' NMR peaks was observed; in some cases, weeks of monitoring were required. Once a solution had reached equilibrium, equilibrium concentrations were calculated from two known quantities: the initial amount of 2MG added to the solution (known by adding a quantified mass of the 2-MG solution whose preparation was described in Sect. 2.4), and the equilibrium concentration of product species (diester, nitrate, sulfate ester) relative to 2-MG (determined by integrations in ${ }^{13} \mathrm{C}$ spectra determined to be quantitatively accurate; see Sect. 2.2). Algebraic manipulation, accounting for the stoichiometry of each 2-MG reaction (R1R4; note that total moles of 2-MG related species are not conserved in the 2-MG-diester forming reactions), gave the following expressions:

$$
\begin{aligned}
& X_{2 \text {-MG-diester }}=X_{2-\mathrm{MG}, i} \times\left(\frac{f_{2 \text {-MG-diester }}}{1+f_{2 \text {-MG-diester }}}\right) \\
& X_{\text {2-MG-sulfate ester }}=X_{2 \text {-MG }, i} \times\left(\frac{f_{2 \text {-MG-sulfate ester }}}{1+f_{2-\text { MG-diester }}}\right)
\end{aligned}
$$

where $f_{2 \text {-MG-diester }}$ and $f_{2 \text {-MG-sulfate ester }}$ are the fraction of initial moles of 2-MG converted to the species 2-MG-diester and 2-MG-sulfate ester, respectively, and $X_{2-\mathrm{MG}, i}$ is the initial mole fraction of 2-MG. The mole fractions of the other relevant species could then be calculated from these mole fractions and the relevant reaction stoichiometry:

$X_{2-\mathrm{MG}}=X_{2-\mathrm{MG}, i}-2 X_{2-\mathrm{MG}-\text { diester }}-X_{2-\mathrm{MG}-\text { sulfate ester }}$

$X_{\mathrm{D}_{2} \mathrm{O}}=X_{\mathrm{D}_{2} \mathrm{O}, i}+X_{2-\mathrm{MG} \text {-diester }}+X_{2-\mathrm{MG} \text {-sulfate ester }}$

where $X_{\mathrm{D}_{2} \mathrm{O}, i}$ is the initial mole fraction of $\mathrm{D}_{2} \mathrm{O}$. Similar relationships were derived for the 2-MG-nitrate ester species in experiments with $\mathrm{DNO}_{3}$ present.

Following from the form of Reaction (R1), equilibrium constants $\left(K_{\text {eq }}^{\prime}\right)$ for 2-MG-diester formation were calculated on a mole fraction basis:

$K_{\text {eq }}^{\prime}=\frac{\left(X_{2-\mathrm{MG}-\text { diester }}\right)\left(X_{\mathrm{D}_{2} \mathrm{O}}\right)}{\left(X_{2-\mathrm{MG}}\right)^{2}}$

The mole fraction data in Table 6 indicates that for the lowest $\mathrm{D}_{2} \mathrm{O}$ mole fraction solution (Solution 7), the amount of 2MG-diester was almost equal to the amount of 2-MG, while for the highest $\mathrm{D}_{2} \mathrm{O}$ mole fraction solution (Solution 3), the 2-MG-diester/2-MG mole fraction ratio was less than $1 \%$.

Following from the form of Reaction (R3), equilibrium constants $\left(K_{\text {eq }}^{\prime}\right)$ for 2-MG-nitrate ester formation were calculated on a mole fraction basis:

$K_{\text {eq }}^{\prime}=\frac{\left(X_{2-\text { MG-nitrate ester }}\right)\left(X_{\mathrm{D}_{2} \mathrm{O}}\right)}{\left(X_{2-\mathrm{MG}}\right)\left(X_{\mathrm{DNO}_{3}}\right)}$

A form of $K_{\mathrm{eq}}^{\prime}$ similar to Eq. (6) was also used for 2-MGsulfate ester formation.

The calculated equilibrium mole fractions for all species and the mole fraction defined $K_{\text {eq }}^{\prime}$ values for the various solutions studied are given in Tables 6 and 8. Since all of the equilibrium data were collected at a single laboratory ambient temperature $(295 \pm 2 \mathrm{~K})$, the data from any one of the individual experiments can be used to calculate the (single) equilibrium constant value that should be valid for all of the experiments. However, due to the significant non-ideality of these experiments, it should not be surprising that the molefraction based $K_{\mathrm{eq}}^{\prime}$ values in Tables 6 and 8 are not a single value. 
Table 7. Equilibrium activities, calculated using AIOMFAC-web, and kinetics information for perchloric acid controlled composition experiments, Solutions 1, 2, 4, 5 and $6 .{ }^{*}$ Activities calculated on a mole fraction basis. ${ }^{* *}$ Activity calculated on a molality basis.

\begin{tabular}{|c|c|c|c|c|c|c|}
\hline Sol'n \# & $a_{2-\mathrm{MG} \text { diester }}{ }^{*}$ & 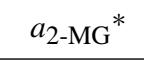 & $a_{\mathrm{D}_{2} \mathrm{O}}{ }^{*}$ & RH (\%) & $a_{D+}{ }^{* *}$ & $k^{\prime}\left(\mathrm{s}^{-1}\right) / 10^{5}$ \\
\hline 1 & 0.00226 & 0.0155 & 0.536 & 53.6 & 35.3 & 8.5 \\
\hline 2 & 0.00528 & 0.0190 & 0.669 & 66.9 & 16.1 & 3.1 \\
\hline 3 & 0.00000486 & 0.00151 & 0.886 & 88.6 & 32.6 & - \\
\hline 4 & 0.00238 & 0.00671 & 0.535 & 53.5 & 34.6 & 7.1 \\
\hline 5 & 0.00319 & 0.00305 & 0.387 & 38.7 & 94.8 & 19.7 \\
\hline 6 & 0.00590 & 0.0186 & 0.669 & 66.9 & 16.2 & 3.2 \\
\hline 7 & 0.000383 & 0.000328 & 0.228 & 22.8 & 284 & - \\
\hline
\end{tabular}

Table 8. Equilibrium mole fraction composition for sulfuric and nitric acid controlled composition experiments. Sum of listed mole fractions not equal to unity due to presence of $\mathrm{NaClO}_{4}$ and trace DSS.

\begin{tabular}{llrrrrrrr}
\hline Sol'n \# & Acid & $X_{2-\mathrm{MG} \text { diester }}$ & $X_{\text {sulf/nit ester }}$ & $X_{2-\mathrm{MG}}$ & $X_{\text {acid }}$ & $X_{\mathrm{D}_{2} \mathrm{O}}$ & $\begin{array}{r}K_{\text {eq }}^{\prime} \\
(2-\mathrm{MG} \leftrightarrow \text { diester })\end{array}$ \\
& & & & & & $\begin{array}{r}K_{\text {eq }}^{\prime} \\
(2-\mathrm{MG} \leftrightarrow \text { sulf/nit ester) }\end{array}$ \\
\hline 8 & $\mathrm{D}_{2} \mathrm{SO}_{4}$ & 0.000105 & 0.00189 & 0.00352 & 0.371 & 0.623 & 5.3 & 0.90 \\
9 & $\mathrm{D}_{2} \mathrm{SO}_{4}$ & 0.000748 & 0.00705 & 0.0137 & 0.359 & 0.617 & 2.5 & 0.88 \\
10 & $\mathrm{D}_{2} \mathrm{SO}_{4}$ & 0.000101 & 0.000175 & 0.0133 & 0.0773 & 0.904 & 0.52 & 0.15 \\
11 & $\mathrm{D}_{2} \mathrm{SO}_{4}$ & 0.00515 & 0.000596 & 0.0651 & 0.106 & 0.805 & 0.98 & 0.15 \\
12 & $\mathrm{D}_{2} \mathrm{SO}_{4}$ & 0.00822 & 0.00243 & 0.0565 & 0.204 & 0.711 & 2.5 & 1.3 \\
13 & $\mathrm{DNO}_{3}$ & 0.000339 & 0.00746 & 0.00903 & 0.382 & 0.594 & 1.9 & 0.19 \\
14 & $\mathrm{DNO}_{3}$ & 0.00803 & 0.00303 & 0.0556 & 0.207 & 0.714 & & \\
\hline
\end{tabular}

In case of the perchloric experiments (in which the only reaction products observed were oligoesters), the activities for each solution component were calculated by inputting the measured equilibrium mole fraction data into AIOMFACweb, which was used as outlined in Sect. 3.4. Because sulfate ester-inorganic and nitrate ester-inorganic interactions are not currently defined in AIOMFAC-web, activities were not calculated for the sulfuric and nitric acid experiments.

Following from the form of Reaction (R1), the equilibrium constant $\left(K_{\text {eq }}\right)$ can also be defined on an activity basis:

$K_{\mathrm{eq}}=\frac{\left(a_{2-\mathrm{MG}-\text { diester }}\right)\left(a_{\mathrm{D}_{2} \mathrm{O}}\right)}{\left(a_{2-\mathrm{MG}}\right)^{2}}$

Table 7 reports AIOMFAC-web-derived activity values calculated for the perchloric acid experiments. The activity based equilibrium constant $\left(K_{\text {eq }}\right)$ was determined by rearranging Eq. (7) and plotting the product $\left(a_{2-\mathrm{MG} \text {-diester }} \times a_{\mathrm{D}_{2} \mathrm{O}}\right)$ vs. $\left(\mathrm{a}_{2-\mathrm{MG}}\right)^{2}$ as in Fig. 6 . The slope of the linear regression is equal to $K_{\text {eq }}$ and was determined to be $8.3 \pm 1.9$ (one standard deviation statistical error) from the data in Table 7. Therefore, at standard conditions (unity activities for all species), 2-MG-diester formation is slightly thermodynamically favored. This result is similar to the finding that the lactic acid oligomerization process is also nearly thermodynamically neutral (Vu et al., 2005).

The range of equivalent $\mathrm{RH}$ values for the solutions studied are $22.8-88.6 \%$ (Table 7 ), which is roughly the same range of $\mathrm{RH}$ commonly observed in the ambient atmosphere.
Therefore, the reported equilibrium constant value has been determined from solutions that possess atmospherically relevant water content. The results are broadly consistent with a previous study of the RH dependence of 2-MG oligoester formation that suggested that monomeric $2-\mathrm{MG}$ is the dominant form of 2-MG-related species for $\mathrm{RH}$ values as low as $13 \%$ (Zhang et al., 2011). These results are also consistent with the low RH $(<10 \%)$ atmospheric chamber experiments in which much higher 2-MG oligoester content was observed (Nguyen et al., 2011; Chan et al., 2010a).

The present equilibrium results can also be reparameterized for use in calculating the equilibrium position of the 2-MG oligomerization process for other water content compositions not directly measured in the present experiments. Since laboratory investigations of SOA processes are generally not able to directly measure the water content of the SOA itself, but rather are able to measure the relative humidity under which the SOA is formed, it is useful to recast Eq. (7) (using the equilibrium relationship of $\mathrm{RH}=a_{\mathrm{H}_{2} \mathrm{O}} \times 100$ ) into the following form,

$$
\frac{\left(a_{2-\mathrm{MG}-\text { diester }}\right)}{\left(a_{2-\mathrm{MG}}\right)^{2}}=\frac{K_{\mathrm{eq}}}{\mathrm{RH}} \times 100
$$

which allows the ratio between the 2-MG-diester activity and the square of the 2-MG activity to be calculated as a function of RH.

Since ambient SOA may contain high inorganic sulfate and/or nitrate content, it is of interest to determine whether 


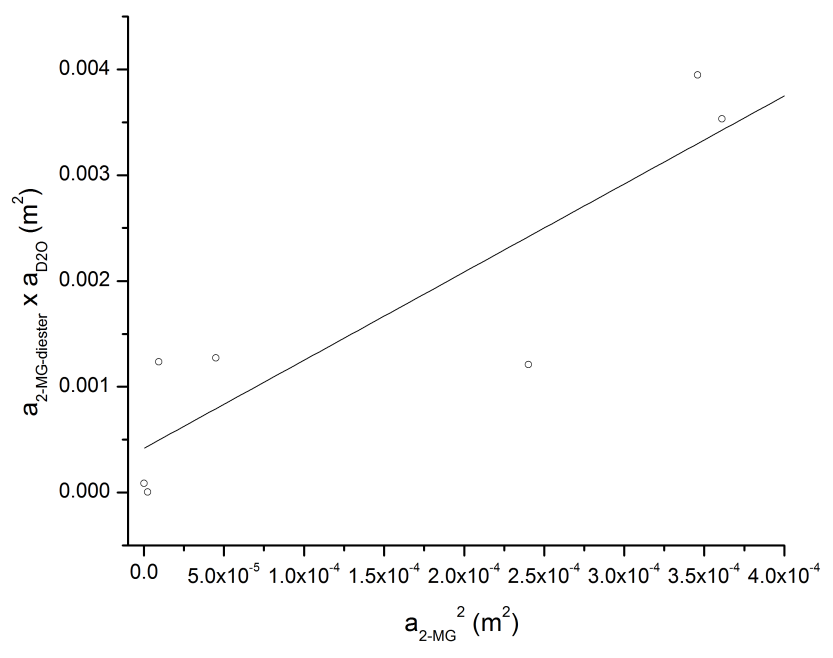

Fig. 6. Equilibrium constant $\left(K_{\mathrm{eq}}\right)$ determination from perchloric acid experiments.

2-MG oligoester or 2-MG nitrate/sulfate ester formation is more thermodynamically favorable. The mole fraction data in Table 7 shows that that both 2-MG-nitrates and 2-MGsulfates are present at lower mole fractions per acid mole fraction than are the 2-MG-diesters per 2-MG mole fraction. Thus, on a constant mole fraction basis, 2-MG-diester formation appears to be thermodynamically favored over both 2-MG-nitrate and 2-MG-sulfate formation.

\subsection{Kinetics of formation of 2-MG diester}

Because Fischer esterification is catalyzed by the protonation of the carbonyl oxygen atom in the carboxylic acid functional group (as depicted in Fig. 1 in the first reaction), the kinetics of 2-MG diester formation is expected to be first order with respect to the proton activity. If this protonation is the rate limiting step, then the kinetics are also expected to be first order with respect to the 2-MG activity. On the other hand, if the reaction of the protonated 2-MG species with an unprotonated 2-MG species (as depicted in Fig. 1 in the second reaction) is the rate limiting step, the kinetics would be expected to be second order with the respect to the 2-MG activity.

In order to determine the order of the esterification reaction with respect to 2-MG experimentally, the 2-MG-diester product formation curves were fit to a first order in 2-MG integrated rate law,

$a_{2-\mathrm{MG} \text {-diester, } t}=a_{2 \text {-MG-diester,eq }} \times\left(1-e^{k^{\prime} t}\right)$

where $a_{2-\mathrm{MG}-\text { diester, } t}$ is the activity of the 2-MG-diester

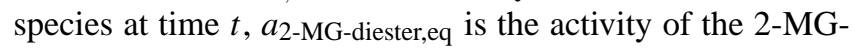
diester species at equilibrium, and $k^{\prime}$ is the pseudo first order rate constant $\left(k^{\prime}=k a_{\mathrm{D}+}\right)$. The 2-MG-diester product formation curves were also fit to a second order in 2-MG integrated rate law,
$a_{2-\mathrm{MG}-\text { diester, } t}=a_{2 \text {-MG-diester,eq }} \times\left(1-\frac{1}{1+k^{\prime} t}\right)$

where $k^{\prime}$ is now the pseudo second order rate constant $\left(k^{\prime}=\right.$ $\left.k a_{\mathrm{D}+}\right)$.

It was found that the best fit was obtained with a rate law that was first order in 2-MG (Eq. 9). Sample curvefitting to first order integrated product rate laws is presented in Fig. 7. Values of $k^{\prime}$ were derived from fitting product formation kinetic data using three carbon atom regions $(\mathrm{COOH}$, primary $\mathrm{COH}$, and tertiary $\mathrm{COH}-$ the methyl region was not analyzed due to peak overlap). Even though it was found that routine ${ }^{13} \mathrm{C}$ NMR relaxation times were not long enough to quantitatively compare product peak integrations in the $\mathrm{COOH}$ and tertiary $\mathrm{COH}$ regions to the 2MG peak integrations for equilibrium calculations, the product formation kinetics, normalized to an extent of reaction

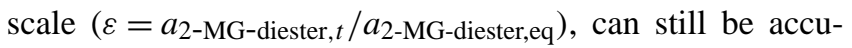
rately extracted. The three $k^{\prime}$ values were in good agreement, and the average of the three $k^{\prime}$ values (which were characterized by an average one standard deviation statistical error of about $30 \%$ ) for each solution is reported in Table 7.

Using the extracted $k^{\prime}$ values for each experiment, a value for the rate constant $k$ then could be determined by plotting $k^{\prime}$ as a function of proton activity $\left(k^{\prime}=k a_{\mathrm{D}+}\right.$; as shown in Fig. 8). Proton activities, calculated using AIOMFAC-web, are given in Table 6 on a molality scale. The kinetics analysis indicates that the rate constant (and one standard deviation statistical error) for the acid-catalyzed formation of the 2MG diester is $(2.09 \pm 0.10) \times 10^{-6} \mathrm{~m}^{-1} \mathrm{~s}^{-1}$.

\section{Atmospheric implications}

The present finding that the activity-based equilibrium constant is near unity $\left(K_{\text {eq }}=8.3\right)$, indicates that the extent of 2-MG oligomerization is predicted to depend almost entirely on the relative activities of 2-MG and water for any given reaction conditions. The equilibrium results are broadly consistent with the extent of 2-MG oligoester formation observed in previous atmospheric chamber investigations of the effect of RH on the extent of SOA formation (Zhang et al., 2011; Nguyen et al., 2011). At the same time, the previous observations of very extensive 2-MG oligomerization in low $\mathrm{RH}$ atmospheric chamber studies (Chan et al., 2010a) are likely directly dependent on experimental conditions in which the SOA water content is extremely low (much lower than that accessed in the present experiments). Therefore, since the various laboratory studies suggest that higher order 2-MG oligoester formation is likely only favored at very low water content and the only ambient aerosol identification for a 2MG oligoester is for the diester species (Jaoui et al., 2008), it seems probable that the formation of 2-MG oligoesters higher than the diester are probably not thermodynamically 

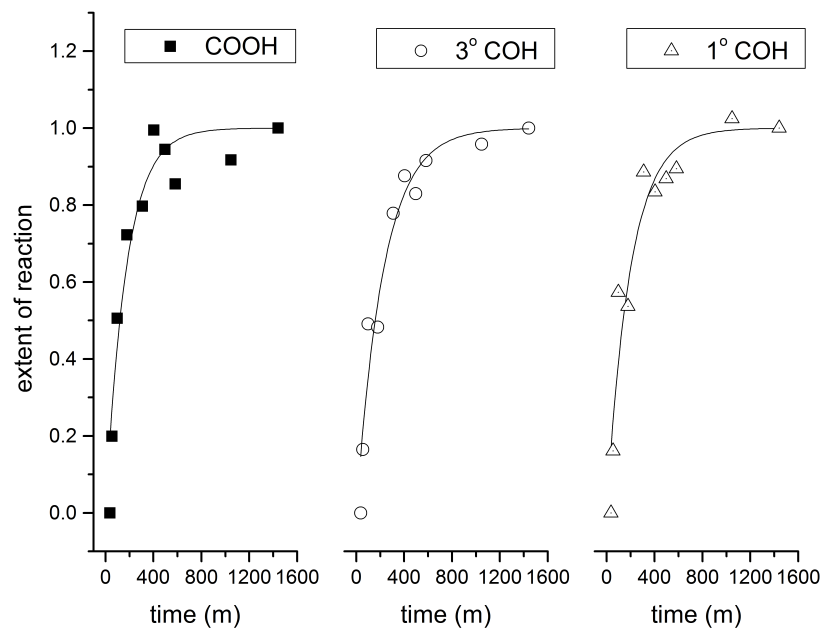

Fig. 7. Sample kinetics plots for single experiment (Solution 1). Solid lines denote first order product formation nonlinear regression results.

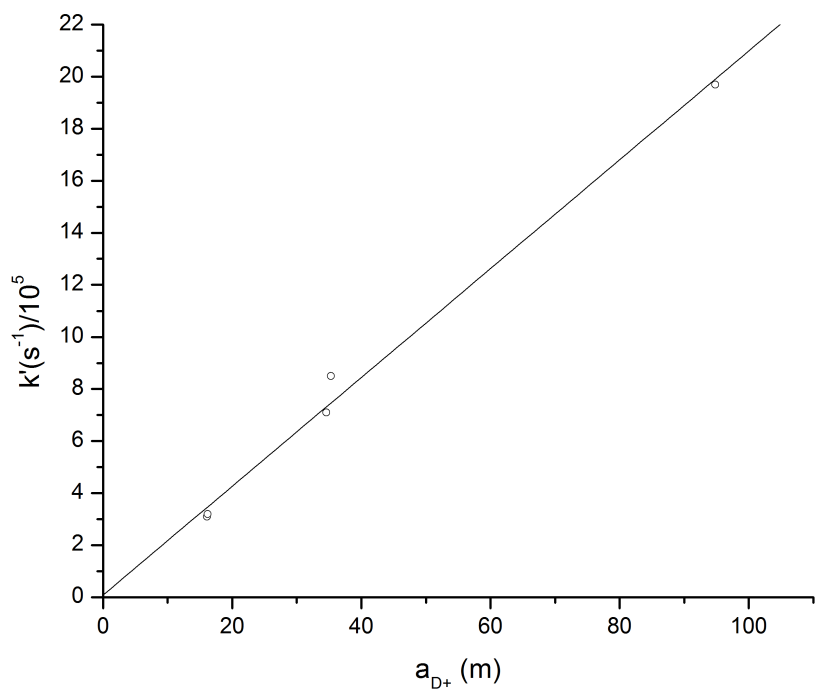

Fig. 8. $k^{\prime}$ for diester formation in $\mathrm{DClO}_{4}$ as a function of AIOMFAC-calculated proton activity (data from Table 7).

favored on SOA at more typical ambient RH values ( $>20 \%)$. It may also be the case that differences in properties between bulk solutions and aerosols could be a factor. For example, the Kelvin effect predicts that a small particle has a higher effective vapor pressure than a corresponding bulk solution of the same composition. Therefore, aerosol particles could have lower water content than is predicted from equilibrium partitioning models, which would favor oligoester formation.

We found that under our controlled experimental conditions of very high strong acid concentration, high 2-MG concentration, and moderate water content, diester formation from 2-MG occurred on time scales ranging from hours to days or weeks. 2-MG sulfate and nitrate ester formation ap-
Table 9. Predicted 2-MG diester production lifetimes as a function of acid content and fixed 2-MG content $\left(X_{2-\mathrm{MG}}=0.07\right)$.

\begin{tabular}{lrrrr}
\hline$X_{\text {acid }}$ & $a_{\mathrm{H}+}(\mathrm{m})$ & equiv pH & lifetime $(\mathrm{h})$ & lifetime $(\mathrm{d})$ \\
\hline $1 \times 10^{-7}$ & $1.21 \times 10^{-5}$ & 4.92 & $1.1 \times 10^{7}$ & $4.6 \times 10^{5}$ \\
0.000001 & 0.00012 & 3.92 & $1.1 \times 10^{6}$ & $4.6 \times 10^{4}$ \\
0.00001 & 0.0012 & 2.93 & $1.1 \times 10^{5}$ & 4697 \\
0.00005 & 0.0057 & 2.24 & $2.3 \times 10^{4}$ & 972 \\
0.0001 & 0.011 & 1.95 & $1.2 \times 10^{4}$ & 498 \\
0.0005 & 0.051 & 1.29 & 2610 & 109 \\
0.001 & 0.10 & 1.02 & 1378 & 57 \\
0.005 & 0.42 & 0.38 & 320 & 13 \\
0.01 & 0.79 & 0.10 & 169 & 7.0 \\
0.02 & 1.56 & -0.19 & 85 & 3.6 \\
0.03 & 2.40 & -0.38 & 55 & 2.3 \\
0.04 & 3.36 & -0.53 & 40 & 1.6 \\
0.05 & 4.47 & -0.65 & 30 & 1.2 \\
0.1 & 13.49 & -1.13 & 9.9 & 0.41 \\
0.2 & 76.87 & -1.89 & 1.7 & 0.072 \\
\hline
\end{tabular}

peared to occur on similar time scales to the 2-MG diester formation. Because we were able to extract a rate constant for the rate determing step of the 2-MG diester formation (the protonation of 2-MG), it is possible to calculate 2-MG diester product formation lifetimes at other acid concentrations. AIOMFAC was used to calculate the proton activities of solutions with a fixed equilibrium $X_{2-\mathrm{MG}}$ value of 0.07 (approximately the highest value used in the present experiments; Solution 1) and with neglect of the effect of diester formation on the proton activities. The proton activities, equivalent $\mathrm{pH}$, and corresponding production lifetimes $\left(\tau=1 / k^{\prime}\right)$ for 2-MG diester formation for several different acid $/ \mathrm{H}_{2} \mathrm{O}$ compositions are given in Table 9. It should be noted that the effect of the presence of high concentrations of 2-MG causes the proton activity to be higher than that for the ideal solution limit; therefore, without the effects of non-ideality, the predicted lifetimes would be even longer. It should also be noted that the estimated self-catalyzed oligomerization lifetime of 3600 days for 2-MG (discussed in Sect. 3.4) falls in the interval between the $\mathrm{pH}=2.2$ and 2.9 solutions, which is on the order of the $\mathrm{pH}$ expected for a concentrated solution of 2-MG $\left(\mathrm{pK}_{\mathrm{a}}\right.$ (lactic acid $\left.)=3.9\right)$ (Dawson et al., 1989). These results suggest that the previous atmospheric chamber studies, which were all conducted with experimental timescales of less than $24 \mathrm{~h}$, would have to have had extremely high SOA acidities in order to facilitate a relative fast Fischer esterification process that could form signficant 2-MG oligoesters on the experimental timescales. It is also apparent that only at the highest acidity values typically observed in ambient SOA ( $\mathrm{pH} \sim 0$ ) (Zhang et al., 2007), is the 2-MG diester production lifetime ( $\sim 7$ days) comparable to typical SOA lifetimes ( $\sim 2$ days). At more typical ambient SOA pH values (1.5-4.0), the 2-MG diester production lifetimes via Fischer esterification appear to be prohibitively long. 


\section{Conclusions}

Our observation of a single 2-MG diester isomer (confirmed with a suite of single and multi-dimensional NMR techniques), in which the esterification was found to have occurred at the primary alcohol group of the alcoholic 2-MG substrate, is consistent with the textbook expectation that Fischer esterification is more facile for unhindered alcohol groups (Loudon, 1984). Furthermore, the observation of this dominant isomer is consistent with earlier findings from MS fragmentation analysis of SOA-phase 2-MG oligoesters formed in atmospheric chamber experiments, which also identified the primary alcohol 2-MG diester isomer as the dominant species (Szmigielski et al., 2007). Therefore, the present study has shown that Fischer esterification does lead to the same 2-MG oligoester linkages as those observed in atmospheric chamber SOA investigations.

While it appears that the present reaction system does lead to 2-MG oligoesters with the same water content equilibrium dependences as observed in atmospheric chamber SOA experiments, the acid-catalyzed kinetics of the mechanism may be too slow to rationalize the 2-MG oligoester production timescales observed in the atmospheric chamber experiments. Furthermore, it appears that unrealistically high ambient SOA acidities would also be required for significant 2-MG oligoester content to arise from a Fischer esterification mechanism in the atmosphere. Therefore, the present results suggest that other, more kinetically facile, esterification mechanisms may be necessary to rationalize the existence of 2-MG oligomers in atmospheric chamber-generated and ambient SOA. These results also highlight the importance of establishing the mechanism by which 2-MG forms from MPAN in the atmosphere.

\section{Supplementary material related to this article is available online at: http://www.atmos-chem-phys.net/13/ 3097/2013/acp-13-3097-2013-supplement.pdf.}

Acknowledgements. This work was supported by the National Science Foundation under Grant Nos. 0753103 and 1153861.

Edited by: F. Keutsch

\section{References}

Braun, S, Kalinowski, H.-O., and Berger, S.: 200 and more NMR experiments, Wiley-VCH, Weinheim, 1998.

Carlton, A. G., Wiedinmyer, C., and Kroll, J. H.: A review of Secondary Organic Aerosol (SOA) formation from isoprene, Atmos. Chem. Phys., 9, 4987-5005, doi:10.5194/acp-9-4987-2009, 2009.
Casale, M., Richman, A., Elrod, M., Garland, R., Beaver, M., and Tolbert, M.: Kinetics of acid-catalyzed aldol condensation reactions of aliphatic aldehydes, Atmos. Environ., 41, 6212-6224, doi:10.1016/j.atmosenv.2007.04.002, 2007.

Chan, A. W. H., Chan, M. N., Surratt, J. D., Chhabra, P. S., Loza, C. L., Crounse, J. D., Yee, L. D., Flagan, R. C., Wennberg, P. O., and Seinfeld, J. H.: Role of aldehyde chemistry and $\mathrm{NO}_{\mathrm{x}}$ concentrations in secondary organic aerosol formation, Atmos. Chem. Phys., 10, 7169-7188, doi:10.5194/acp-10-7169-2010, 2010a.

Chan, M. N., Surratt, J. D., Claeys, M., Edgerton, E. S., Tanner, R. L., Shaw, S. L., Zheng, M., Knipping, E. M., Eddingsaas, N. C., Wennberg, P. O., and Seinfeld, J. H.: Characterization and quantification of isoprene-derived epoxydiols in ambient aerosol in the southeastern United States, Environ. Sci. Technol., 44, 45904596, 2010 b.

Cole-Filipiak, N. C., O'Connor, A. E., and Elrod, M. J.: Kinetics of the hydrolysis of atmospherically relevant isoprene-derived hydroxy epoxides, Environ. Sci. Technol., 44, 6718-6723, 2010.

Cox, R. A. and Yates, K.: Excess acidities. A generalized method for the determination of basicities in aqueous acid mixtures, J. Am. Chem. Soc., 100, 3861-3867, 1978.

Darer, A. I., Cole-Filipiak, N. C., O'Connor, A. E., and Elrod, M. J.: Formation and stability of atmospherically relevant isoprenederived organosulfates and organonitrates, Environ. Sci. Technol., 45, 1895-1902, 2011.

Dawson, R. M. C., Elliott, D. C., and Elliott, W. H.: Data for biochemical research, Clarendon Press, Gloucestershire, United Kingdom, 1989.

Espartero, J. L., Rashkov, I., Li, S. M., Manolova, N., and Vert, M.: NMR analysis of low molecular weight poly(lactic acid)s, Macromolecules, 29, 3535-3539, 1996.

Filachione, E. M. and Fisher, C. H.: Lactic acid condensation polymers, Ind. Eng. Chem., 36, 223-228, 1944.

Gómez-González, Y., Surratt, J. D., Cuyckens, F., Szmigielski, R., Vermeylen, R., Jaoui, M., Lewandowski, M., Offenberg, J. H., Kleindienst, T. E., Edney, E. O., Blockhuys, F., Van Alsenoy, C., Maenhaut, W., and Claeys, M.: Characterization of organosulfates from the photooxidation of isoprene and unsaturated fatty acids in ambient aerosol using liquid chromatography/(-) electrospray ionization mass spectrometry, J. Mass Spectrom., 43, 371-382, doi:10.1002/jms.1329, 2008.

Guenther, A., Karl, T., Harley, P., Wiedinmyer, C., Palmer, P. I., and Geron, C.: Estimates of global terrestrial isoprene emissions using MEGAN (Model of Emissions of Gases and Aerosols from Nature), Atmos. Chem. Phys., 6, 3181-3210, doi:10.5194/acp-63181-2006, 2006.

Hallquist, M., Wenger, J. C., Baltensperger, U., Rudich, Y., Simpson, D., Claeys, M., Dommen, J., Donahue, N. M., George, C., Goldstein, A. H., Hamilton, J. F., Herrmann, H., Hoffmann, T., Iinuma, Y., Jang, M., Jenkin, M. E., Jimenez, J. L., Kiendler-Scharr, A., Maenhaut, W., McFiggans, G., Mentel, Th. F., Monod, A., Prévôt, A. S. H., Seinfeld, J. H., Surratt, J. D., Szmigielski, R., and Wildt, J.: The formation, properties and impact of secondary organic aerosol: current and emerging issues, Atmos. Chem. Phys., 9, 5155-5236, doi:10.5194/acp-9-51552009, 2009.

Hatch, L. E., Creamean, J. M., Ault, A. P., Surratt, J. D., Chan, M. N., Seinfeld, J. H., Edgerton, E. S., Su, Y., and Prather, K. A.: Measurements of Isoprene-Derived Organosulfates in Ambient 
Aerosols by Aerosol Time-of-Flight Mass Spectrometry - Part 1: Single Particle Atmospheric Observations in Atlanta, Environ. Sci. Technol., 45, 5105-5111, doi:10.1021/es103944a, 2011.

Jaoui, M., Edney, E. O., Kleindienst, T. E., Lewandowski, M., Offenberg, J. H., Surratt, J. D., and Seinfeld, J. H.: Formation of secondary organic aerosol from irradiated $\alpha$-pinene/toluene/NOx mixtures and the effect of isoprene and sulfur dioxide, J. Geophys. Res., 113, D09303, doi:10.1029/2007jd009426, 2008.

Loudon, G. M.: Organic Chemistry, Addison-Wesley, Reading, Massachusetts, 1984.

Minerath, E. C., Casale, M. T., and Elrod, M. J.: Kinetics feasibility study of alcohol sulfate esterification reactions in tropospheric aerosols, Environ. Sci. Technol., 42, 4410-4415, 2008.

Minerath, E. C., Schultz, M. P., and Elrod, M. J.: Kinetics of the reactions of isoprene-derived epoxides in model tropospheric aerosol solutions, Environ. Sci. Technol., 43, 8133-8139, doi:10.1021/es902304p, 2009.

Nguyen, T. B., Roach, P. J., Laskin, J., Laskin, A., and Nizkorodov, S. A.: Effect of humidity on the composition of isoprene photooxidation secondary organic aerosol, Atmos. Chem. Phys., 11, 6931-6944, doi:10.5194/acp-11-6931-2011, 2011.

Surratt, J. D., Murphy, S. M., Kroll, J. H., Ng, N. L., Hildebrandt, L., Sorooshian, A., Szmigielski, R., Vermeylen, R., Maenhaut, W., Claeys, M., Flagan, R. C., and Seinfeld, J. H.: Chemical Composition of Secondary Organic Aerosol Formed from the Photooxidation of Isoprene, J. Phys. Chem. A, 110, 9665-9690, doi:10.1021/jp061734m, 2006.

Surratt, J. D., Kroll, J. H., Kleindienst, T. E., Edney, E. O., Claeys, M., Sorooshian, A., Ng, N. L., Offenberg, J. H., Lewandowski, M., Jaoui, M., Flagan, R. C., and Seinfeld, J. H.: Evidence for organosulfates in secondary organic aerosol, Environ. Sci. Technol., 41, 517-527, 2007a.

Surratt, J. D., Lewandowski, M., Offenberg, J. H., Jaoui, M., Kleindienst, T. E., Edney, E. O., and Seinfeld, J. H.: Effect of acidity on secondary organic aerosol formation from isoprene, Environ. Sci. Technol., 41, 5363-5369, 2007b.

Surratt, J. D., Chan, A. W. H., Eddingsaas, N. C., Chan, M., Loza, C. L., Kwan, A. J., Hersey, S. P., Flagan, R. C., Wennberg, P. O., and Seinfeld, J. H.: Reactive intermediates revealed in secondary organic aerosol formation from isoprene, Proc. Natl. Acad. Sci., 107, 6640-6645, 2010.
Szmigielski, R., Surratt, J. D., Vermeylen, R., Szmigielska, K., Kroll, J. H., Ng, N. L., Murphy, S. M., Sorooshian, A., Seinfeld, J. H., and Claeys, M.: Characterization of 2-methylglyceric acid oligomers in secondary organic aerosol formed from the photooxidation of isoprene using trimethylsilylation and gas chromatography/ion trap mass spectrometry, J. Mass Spectrom., 42, 101-116, doi:10.1002/jms.1146, 2007.

Vu, D. T., Kolah, A. K., Asthana, N. S., Peereboom, L., Lira, C. T., and Miller, D. J.: Oligomer distribution in concentrated lactic acid solutions, Fluid Phase Equilib., 236, 125-135, doi:10.1016/j.fluid.2005.06.021, 2005.

Weber, A. L.: Thermal synthesis and hydrolysis of polyglyceric acid, Orig. Life Evol. Biosph., 19, 7-19, 1989.

Zhang, H., Surratt, J. D., Lin, Y. H., Bapat, J., and Kamens, R. M.: Effect of relative humidity on SOA formation from isoprene/NO photooxidation: enhancement of 2-methylglyceric acid and its corresponding oligoesters under dry conditions, Atmos. Chem. Phys., 11, 6411-6424, doi:10.5194/acp-11-6411-2011, 2011.

Zhang, Q., Jimenez, J. L., Worsnop, D. R., and Canagaratna, M.: A case study of urban particle acidity and its influence on secondary organic aerosol, Environ. Sci. Technol., 41, 3213-3219, 2007.

Zuend, A. and Seinfeld, J. H.: Modeling the gas-particle partitioning of secondary organic aerosol: the importance of liquidliquid phase separation, Atmos. Chem. Phys., 12, 3857-3882, doi:10.5194/acp-12-3857-2012, 2012.

Zuend, A., Marcolli, C., Luo, B. P., and Peter, T.: A thermodynamic model of mixed organic-inorganic aerosols to predict activity coefficients, Atmos. Chem. Phys., 8, 4559-4593, doi:10.5194/acp8-4559-2008, 2008.

Zuend, A., Marcolli, C., Peter, T., and Seinfeld, J. H.: Computation of liquid-liquid equilibria and phase stabilities: implications for RH-dependent gas/particle partitioning of organic-inorganic aerosols, Atmos. Chem. Phys., 10, 7795-7820, doi:10.5194/acp10-7795-2010, 2010.

Zuend, A., Marcolli, C., Booth, A. M., Lienhard, D. M., Soonsin, V., Krieger, U. K., Topping, D. O., McFiggans, G., Peter, T., and Seinfeld, J. H.: New and extended parameterization of the thermodynamic model AIOMFAC: calculation of activity coefficients for organic-inorganic mixtures containing carboxyl, hydroxyl, carbonyl, ether, ester, alkenyl, alkyl, and aromatic functional groups, Atmos. Chem. Phys., 11, 9155-9206, doi:10.5194/acp11-9155-2011, 2011. 